\title{
A IMIGRAÇ̃̃O DOS SUÁBIOS DO DANÚBIO E AS DISCUSSÕES PELAS TERRAS DE ENTRE RIOS, GUARAPUAVA, PARANÁ
}

\author{
THE IMMIGRATION OF SUÁBIOS OF DANÚBIO AND DISCUSSIONS \\ BY LAND OF ENTRE RIOS, GUARAPUAVA, PARANÁ
}

\author{
Rodrigo dos SANTOS ${ }^{1}$
}

\begin{abstract}
RESUMO
O presente artigo analisa a imigração de um grupo específico de refugiados da Segunda Guerra Mundial, denominado de Suábios do Danúbio. Esse grupo veio, com o auxílio de organizações internacionais, para o distrito de Entre Rios, localizado no município de Guarapuava, Paraná. Contudo, tais terras eram habitadas por fazendeiros e por um grupo de descendentes de ex-escravos, o que promoveu alguns conflitos, que permanecem até os dias atuais. Para analisar tal situação, são utilizadas bibliografias sobre o tema e algumas edições do periódico Folha do Oeste, produzido no referido município, além de notícias atuais acerca da temática.
\end{abstract}

Palavras-chave: Conflitos; Deslocados de guerra; Refugiados; Segunda Guerra Mundial.
Recebido em: 13/04/2015

Aprovado em: 26/05/2016

\begin{abstract}
This article analyzes the migration of a specific group of displaced by World War II called the Suábios do Danúbio. This group came with the help of international organizations for Entre Rios District in Guarapuava, Paraná. However, these lands were inhabited by farmers and a group of former slave descendants, which promoted some conflicts, which remain to this day. To analyze this situation, bibliographies are used on the subject and some editions of the journal Folha do Oeste, produced in the municipality, as well as current news about the theme.
\end{abstract}

Keywords: Conflicts; Displaced persons; Refugees; World War II.

\footnotetext{
${ }^{1}$ Graduado em História (UNICENTRO), especialista em Educação do Campo (ESAP) e Docência do Ensino Superior (UNOPAR) e mestre em História (UNICENTRO). Atualmente é professor substituto na Universidade Federal da Fronteira Sul (UFFS).E-mail: digao_santos9@hotmail.com. 


\section{Introdução}

$\mathrm{O}$ presente texto analisa a imigração, ocorrida em 1951, de um grupo de refugiados, denominado de Suábios do Danúbio ${ }^{2}$, dos campos de refugiados da Áustria para o distrito de Entre Rios, situado no município de Guarapuava, Paraná $^{3}$, e as discussões que se desenrolaram a partir desse fenômeno, principalmente com a desapropriação das terras do referido distrito. As discussões entre fazendeiros, Suábios, Governo do Paraná e descendentes de escravos do Paiol de Telha ${ }^{4}$ tiveram início na década de 1950 e arrastam-se até os dias atuais.

Para compreender tais acontecimentos, optou-se prioritariamente por utilizar como fontes matérias ${ }^{5}$ jornalísticas que apresentam afinidade com a temática da imigração dos Suábios do Danúbio. Nesse sentido, na análise da imprensa periódica, metodologicamente empregam-se os elementos de pesquisa em jornais (periódicos) propostos por Luca (2008) e Santos (2015a).

Com relação à estrutura do trabalho, este se divide em três momentos. No primeiro momento, apresentam-se aspectos da imigração para o Brasil dos Suábios do Danúbio em 1951; em um segundo momento, abordam-se a desapropriação e as indenizações das terras do Distrito de Entre Rios, que o transformaram em Colônia Entre Rios; e, em um terceiro momento, discorre-se acerca das terras da comunidade quilombola Paiol de Telha e das discussões, presentes até os dias atuais, sobre a ocupação dessas terras

${ }^{2}$ Segundo Stein (2011, p. 25), os Suábios do Danúbio também se intitulam Donauschwaben

${ }^{3}$ Outros grupos de imigrantes também vieram para o Município de Guarpauava no contexto da Segunda Guerra Mundial, como a Família Egert de etnia Polonesa/Alemã, fixada no distrito de Rio das Pedras (SANTOS, 2015b)

${ }^{4}$ Encontraram-se as designações Paiol de Telha e Paiol de Terras, optando-se pela grafia no singular devido à presença desta forma em documentos oficiais.

${ }^{5}$ Rabaça e Barbosa (2004) apresentam a diferenciação entre matéria e reportagem. Segundo os autores, matéria é qualquer escrito jornalístico, enquanto que reportagem é um escrito mais elaborado com a ida a campo do jornalista.

do jornalista.

'No final do texto História dos, nos e por meio dos periódicos, a autora apresenta um quadro com alguns procedimentos que podem ser utilizados para a análise dos periódicos: atentar para as características materiais da obra (suporte, papel e periodicidade) e para a organização interna do conteúdo, caracterizar o grupo responsável pela sua coordenação e analisar todo o material de acordo com a problemática escolhida etc.

\section{A imigração dos Suábios do Danúbio}

A explicação sobre a denominação Suábios do Danúbio é efetuada por Elfes (1971) em sua obra Suábios no Paraná. Os imigrantes eram originários, em grande parte, da Suábia e, depois, fixaram-se nas margens do Rio Danúbio $^{7}$. Além disso, esse grupo tem histórico de migração por várias localidades da Europa, pois inicialmente se instalaram em uma região do Antigo Império Austro-Húngaro, vindo de várias províncias do até então Reino Alemão, tais como Suábia, Bavária e Francônia. Essas imigrações originaram outras, acompanhando as margens do Rio Danúbio. Com o fim desse tipo de migração, esse grupo se aliou a outros grupos de diversas nacionalidades.

No fim da Primeira Guerra Mundial (1914-1918), ainda segundo Elfes (1971), o território Austro-Húngaro foi dividido, originando a Iugoslávia, Romênia e Hungria e dispersando o grupo dos Suábios. Com a Segunda Guerra (1939-1945), os alemães nazistas promoveram movimentos migratórios na região, ocupando as terras dos habitantes daquela localidade. Depois, com a retirada dos nazistas e com a chegada dos russos, a maioria dos Suábios abandonou a localidade, temendo revanche dos russos. Os que permaneceram foram expulsos pelos russos; sem ter para onde ir, foram recebidos pela Áustria em campos de refugia$\operatorname{dos}^{8}$. Posteriormente, o Governo Suíço compadeceu-se com a situação dos refugiados na Áustria e, com a ajuda de organizações internacionais, promoveu a imigração de parte desse grupo para o Brasil, especialmente para Guarapuava, Paraná, na localidade de Entre Rios.

$\mathrm{O}$ procedimento adotado para a vinda dos Suábios também foi destacado por Elfes (1971), que explica que eles

Gärtner (2014) entende que, diferente de outros grupos imigratórios que se denominam a partir de sua etnia enquanto nacionalidade, os Suábios do Danúbio encontram sua identidade enraizada no seu local de origem, uma província do Reino Alemão, e no Rio Danúbio.

${ }^{8}$ Segundo Elfes (1971), a ordem dada aos Suábios foi que só levassem o que conseguissem carregar. 
não tinham como objetivo a fixação no Estado do Paraná. A organização Ajuda Suiça para a Europa enviou um grupo para viabilizar a imigração dos Suábios em 1949, o qual observou, em um primeiro momento, as terras de Goiás pelo fato de mais de $60 \%$ das terras deste Estado pertencerem ao Governo Brasileiro. Entretanto, a localidade não tinha facilidade para o escoamento da produção dos possíveis novos habitantes. Diante disso, a segunda opção foi o Paraná, tendo os Suábios do Danúbio escolhido as terras de Entre Rios, depois de rejeitadas pela comissão de avaliação as terras de Clevelândia, Goioxim e Fazenda Sobral, localizadas nas proximidades de Guarapuava.

A imigração dos Suábios do Danúbio ao distrito de Entre Rios também foi noticiada pela imprensa ${ }^{9}$, especialmente pelo jornal local, denominado Folha do Oeste ${ }^{10}$. Esse semanário apresentou três matérias sobre os imigrantes em 10 de junho de 1951. Em uma delas, intitulada Colonos para Guarapuava, alguns dados mostram como foi o processo de imigração dos Suábios:

Estão chegando em nossa cidade os primeiros grupos de emigrantes de raça germânica para a colonisação dos campos de Entre Rios.

Sexta - feira última, chegaram 220 pessôas, entre as quais, técnicos para o início da construção de casas de madeira, para que, dentro de um mês, os colonos já estejam alojados em suas casas (FOLHA DO OESTE, 10/06/1951-a) ${ }^{11}$.

A matéria promove confusão com as convenções aceitas sobre o termo imigração e emigração. Segundo Santos (1997), a emigração refere-se à visão do migrante em seu local de origem; já a imigração é a visão do migrante no seu local de destino, na sua nova morada.

${ }^{9}$ Santos (2015a) afirma que, além do jornal Folha do Oeste, a notícia da chegada dos Suábios do Danúbio foi noticiada pelo jornal $O$ Estado de São Paulo e o Diário do Pioneiro de Caxias do Sul, Estado do Rio

Grande do Sul.
${ }^{10}$ O historiador Maria (2011) apresenta alguns elementos sobre o jornal Folha do Oeste: o referido semanário foi fundado pelo empresário e Deputado Estadual Antonio Lustosa de Oliveira, tendo início em 1937 e término em 1981, figurando como o principal periódico guarapuavano e inovando ao ser o primeiro da localidade a apresentar imagens.

${ }^{11}$ Nas citações dos jornais, optou-se pela grafia original.
Nesse sentido, a matéria deveria utilizar o termo imigração, pois se apresenta a percepção dos Suábios a partir de seu destino, o município de Guarapuava.

Nesta mesma edição, encontramse mais duas matérias sobre a imigração dos Suábios. Na matéria intitulada Colônia em Entre Rios, destaca-se a importância da vinda dos imigrantes:

Finalmente estão aplainados todos os entráves que vinham sendo apóstos ao grande e oportuno empreendimento, em bôa hora resolvido, para a colonisação dos váles dos rios Jordão e Pinhão, destinados á incentivar a cultura do preciso Cereal, que tem sido o maior problema no setôr produção e que também é um dos maióres gravâmes á nossa economia, - o trigo (FOLHA DO OESTE, 10/06/1951-b).

Nesse trecho, apresenta-se a importância para os brasileiros da imigração dos Suábios, uma vez que estes trariam as técnicas para o plantio de trigo. Assim, os Suábios viriam para contribuir no aumento da produção de cereal, que, segundo a matéria, era escasso no Paraná e possivelmente no país. Esse mesmo trecho também expressa a localização da Colônia Entre Rios, situada entre os Rios Jordão e Pinhão, no distrito de Entre Rios, terras que já tinham habitantes, levando a entraves para que fossem desapropriadas.

Os entraves sobre a vinda dos Suábios motivaram a publicação de várias matérias no semanário Folha do Oeste. A primeira que se refere a esse problema foi um dos discursos pronunciados pelo Deputado Antonio Lustosa de Oliveira ${ }^{12}$ na Assembleia Legislativa do Paraná e publicado nesta mesma edição como uma republicação do jornal Gazeta do Povo ${ }^{13}$ da Capital do Esta-

\footnotetext{
${ }^{12}$ A pesquisadora Silva (2010) apresenta aspectos políticos da carreia de Antonio Lustosa de Oliveira. Segundo ela, Lustosa foi Prefeito Municipal, Deputado Estadual e Federal e Presidente do Diretório do Partido Socialista Democrático (PSD), além de proprietário da Rádio Difusora de Guarapuava, da Gráfica Guairacá e do jornal Folha do Oeste.

${ }^{13}$ Segundo Oliveira e Barbosa (2011), o jornal Gazeta do Povo teve seu primeiro número editado em 3 de fevereiro de 1919 por Benjamin Lins e Plácido e Silva, sendo considerado o maior jornal do Estado do Parana em tiragem, divulgação e circulação.
} 
do (Curitiba) (STEIN, 2011, p. 106). A informação trazida pela matéria era de que as terras foram desapropriadas pelo Governo do Paraná pelo Decreto $\mathrm{n}^{\circ}$. 1.229 , de 18 de maio de 1951.

Outros dados apontam as famílias que teriam suas terras desapropriadas:

Sr. Presidente, diante dêsse episodio marcante, dessa admiravel atitude demonstrada pelos fazendeiros guarapuavanos, não podemos permanecer em silencio, usando esta tribuna para congratular-mo-nos, entusiasticamente, com aqueles bravos descendentes dos Siqueira Cortes, dos Lustosa, dos Martins, dos Ferreira Caldas e dos Rivas, pela deliberação que tiveram despojando-se de suas propriedades tradicionais, para nelas serem localizados outros lutadores, que desejam produzir nos campos guaracáenses o miraculoso grão do trigo, em tal quantidade, capaz de abastecer não só as populações do oeste, como as de outras regiões do Estado (FOLHA DO OESTE, 10/06/1951-c).

O trecho em questão sobre a imigração dos Suábios possui três aspectos que merecem observação. $\mathrm{O}$ primeiro refere-se, mais uma vez, ao fato de que os mesmos viriam cultivar o trigo, auxiliando no abastecimento de toda a região de Guarapuava. Com relação à designação populações do oeste, esta se deve ao fato de que, naquele período, o município possuía terras em grande quantidade no oeste do Estado, de modo que os imigrantes auxiliariam na produção não só nesta localidade, mas em todas as regiões do país, com o intuito de produzir em larga escala, principalmente trigo ${ }^{14}$.

$\mathrm{O}$ segundo aspecto consiste na designação de lutadores conferida aos imigrantes Suábios do Danúbio. Infere-se, a partir das contribuições de Shephard (2012), que os Suábios viveram, como milhões de deslocados pela Segunda Guerra Mundial, em situações

${ }^{14} \mathrm{~A}$ relevância da vinda dos Suábios para a plantação do trigo também foi apontada por Stein (2011) e Elfes (1971). Os imigrantes do pós-guerra tiveram dois destinos principais no Brasil: São Paulo, para auxiliarem na industrialização, e Paraná, para trabalharem na agricultura (SANTOS, 2015a). de grande miserabilidade em campos de refugiados. O historiador britânico aponta que muitos campos de refugiados em alguns momentos lembravam os campos de concentração criados pela Alemanha Nazista para aprisionar judeus, homossexuais e ciganos. A lembrança deve-se às péssimas condições de higiene e à carência de alimentos, fornecidos pelas organizações internacionais que gerenciavam os campos.

O terceiro aspecto a ser ressaltado informa o nome da família de Lustosa como uma das atingidas pela desapropriação. Torna-se importante recordar que o Deputado Antonio Lustosa de Oliveira também foi proprietário do jornal Folha do Oeste, o que evidencia uma posição política do referido periódico em acompanhar os desencadeamentos da imigração dos Suábios do Danúbio, já que o mantedor desse veículo de imprensa tinha interesses pelas desapropriações e indenizações ${ }^{15}$.

Diante disso, percebe-se que a imigração dos Suábios do Danúbio foi importante, principalmente para suprir a carência de trigo no Estado, colaborando tanto para os refugiados de guerra que precisavam de uma nova morada quanto para toda a população que tinha interesse na produção do trigo. Apesar disso, a vinda desses imigrantes motivou discussões sobre a posse da terra que estes escolheram para habitar, o distrito de Entre Rios. Essas discussões foram apresentadas, em sua maioria, no jornal Folha do Oeste, de propriedade do Deputado Antonio Lustosa de Oliveira, que possuía também interesse nas indenizações sobre as desapropriações, pois suas terras foram atingidas. Esses conflitos são analisados no tópico seguinte deste trabalho.

\section{A posse de terras em Entre Rios na década de 1950}

A partir do semanário Folha do

${ }^{15}$ Segundo Santos (2015a), Antonio Lustosa de Oliveira recebeu terras no atual município de Douradina (Paraná) como permuta pelas terras de Entre Rios. 
Oeste, visualizam-se os conflitos sobre a posse da localidade de Entre Rios, situada em Guarapuava. Os conflitos, que não foram físicos, mas ideológicos, envolveram o Governo do Estado do Paraná, a Cooperativa que representava os Suábios, os fazendeiros e os descendentes de ex-escravos.

O jornal Folha do Oeste teve um intervalo na publicação de suas edições no final de 1951 (ano em que vieram os Suábios), retornando à atividade em 1953, mas voltando a tratar da posse das terras apenas em 1954. A primeira matéria que apresenta os detalhes sobre os conflitos data de 13 de junho de 1954 e consiste, novamente, em um pronunciamento do Deputado Antonio Lustosa de Oliveira na Assembleia Legislativa do Paraná. A matéria, intitulada Defendendo os interesses de Guarapuava, inicia com um ditado popular e, em seguida, apresenta o objetivo do pronunciamento:

Acreditando no antigo adagio popular, 'que água mole em pedra dura, tanto bate, até que fura', é que nos animamos, pela terceira vez, debater, desta tribuna, o assunto que diz respeito à injustificável procrastinação da execução da Lei n. 962, sancionada em 17 de outubro de 1952, pelo ilustre Governador do Estado, dr. Bento Munhoz da Rocha Neto (FOLHA DO OESTE, 13/06/1954).

Essa matéria demonstra a terceira tentativa de cobrança sobre a indenização para os desapropriados do distrito de Entre Rios, motivada pela Lei $n^{\circ} .962$, de 17 de outubro de 1952, promulgada quase dois anos após a imigração dos Suábios. A referida Lei foi sancionada pelo Governador Bento Munhoz da Rocha Neto e não foi aplicada, ficando os proprietários daquela localidade sem as indenizações, como informa outro trecho da mesma matéria: "Essa citada Lei [...] refere-se a concessão da área de 25 hectares de terras devolutas localisadas na Colônia Piquirí, no Município de Guarapuava" (FOLHA DO OESTE, 13/06/1954).
Outro trecho da mesma matéria menciona a ocorrência de uma situação inversa a do ano de 1951. Enquanto que, em 1951, os fazendeiros abdicaram de suas terras em favor dos imigrantes internacionais, em 1954, Lustosa afirma que os imigrantes cederam parte de suas terras para os fazendeiros: "é o estrangeiro $^{16}$ recém-chegado em nossa terra, que numa demonstração de solidariedade humana, procura amparar cerca de 40 famílias de paupérrimos caboclos brasileiros" (FOLHA DO OESTE, $13 / 06 / 1954)$. Por meio desse fragmento, percebe-se que possivelmente não foram todos os fazendeiros que ficaram sem suas terras, uma vez que apenas 40 famílias ficaram sem receber as indenizações prometidas, famílias essas que o jornal denomina de paupérrimos caboclos brasileiros, ou seja, moradores do campo com pouco poder aquisitivo.

A matéria encerra com alguns apelos ao Presidente da Assembleia Legislativa do Paraná: "Sr Presidente, não queremos crer, que estejamos 'gritando no deserto', porisso, levamos ao conhecimento das autoridades responsáveis, os angustiosos apelos das sacrificadas populações interioranas" (FOLHA DO OESTE, 13/06/1954). Antonio Lustosa acreditava que os apelos feitos na bancada da Assembleia seriam atendidos prontamente, sendo encaminhados para os responsáveis tomarem as devidas providências.

Em outubro do mesmo ano, Lustosa novamente se pronuncia na Tribuna da Assembleia Legislativa do Estado em favor dos Suábios. Nessa matéria, destaca-se a dificuldade de fornecimento de adubos para a Colônia Entre Rios, bem como as discussões sobre a posse de terras em Entre Rios. A matéria foi apresentada, em posição de destaque, na primeira página do semanário Folha do Oeste:

Outra circunstância que está contribuindo para o desespero, dificuldades, e quiçá, do desaparecimento da grande colonização de imigrantes

${ }^{16}$ Em outra publicação, discutiram-se as denominações imigrante, estrangeiro e alienígena (SANTOS; ALMEIDA; SCHÖRNER, 2015). 
alemães localizada em terras guarapuavanas, é que se prende a morosidade injustificável ou melhor, a reconhecida má vontade dos atuais responsáveis pela pública administração paranaense, para com a Cooperativa Agrária Limitada, entidade que superintende todas as atividades da mencionada colônia (FOLHA DO OESTE, 31/10/1954).

Segundo essa matéria, ocorreu uma má vontade do governo paranaense com relação aos Suábios, tendo em vista a ausência de adubos e a demora não justificada para resolver a questão das indenizações das terras. Em função de tal dificuldade, possivelmente essa comunidade de imigrantes poderia desaparecer, originando alguns problemas de abastecimento de alimentos, tendo em vista que a Colônia contribuía para o suprimento de trigo no Estado ${ }^{17}$.

Outro trecho da mesma matéria detalha outras informações sobre o ocorrido:

Acontece que, quando essa colmeia de trabalhadores se estabeleceram em Guarapuava, foram adquiridas diversas áreas de terras pertencentes a proprietários que não se sujeitam, como os demais, a vender suas antigas e tradicionais propriedades, em troca de compensação oferecida pelo govêrno, em terras no norte do Estado.

Diante desse imperativo, a Cooperativa Agrária Limitada adquiriu àquelas propriedades dos fazendeiros guarapuavanos, na esperança de ressarcir o capital empatado com o pronto recebimento das terras do norte, tudo de acordo com a escritura de compromisso firmada em 7 de dezembro de [19] 51, entre o govêrno do Estado, os fazendeiros guarapuavanos e a dita Cooperativa Agrária (FOLHA DO OESTE, 31/10/1954).

Alguns fazendeiros não cederam para o Estado do Paraná suas terras em favor dos imigrantes, com o receio de que o governo não honrasse seu com-

17 Elfes (1971) afirma que, por dificuldades financeiras, alguns imigrantes, tanto na década de 1950 quanto em anos posteriores, foram para São Paulo ou retornaram para a Alemanha. promisso de entregar terras devolutas no norte do Estado para o cultivo do café. Diante disso, optaram por firmar um contrato que estabelecia que as terras seriam compradas pela Cooperativa dos Imigrantes Suábios e que estes ficariam com as terras do norte, vendendo -as a terceiros. Novamente, o governo do período não solucionou a permuta das terras, ficando os Suábios sem a oportunidade de efetuar o negócio dessas terras. A matéria de outubro de 1954 aponta que esse acordo foi feito por meio de uma escritura de compromisso.

Em 1955, outra matéria do jornal Folh a do Oeste refere-se aos fazendeiros que entregaram suas terras ao governo do Estado: "os infortunados fazendeiros guarapuavanos, que entregaram as suas antigas Fazendas de criar, afim de que o Govêrno nelas localizasse os emigrantes europeu, esperam, desde 1951, a prometida e imediata titulação das terras" (FOLHA DO OESTE, 03/07/1955) ${ }^{18}$. Na mesma matéria, informa-se que alguns lotes foram titulados: "A medição das terras devolutas foi executada e aprovada por sentença governamental, estando alguns lótes pagos e já titulados, e outros, dependendo de simples despacho dos requerimentos" (FOLHA DO OESTE, 03/07/1955).

Em agosto de 1955, outro episódio foi noticiado pela Folha do Oeste, agora tratando dos fazendeiros agregados de Entre Rios: "Dentre os temas debatido, figura, a situação angustiante dos 'agregados' da Fazenda Entre Rios que há longos anos permaneceram na expectativa de serem localizados na colônia estadual de Marquinho" (FOLHA DO OESTE, 07/08/1955). Essa nova ação não foi executada, como aponta Silva (2010, p. 146): "Entretanto, apesar de apelos do deputado, o projeto não foi aprovado pelo governo do Estado, e não há registros do destino tomado por essas famílias de agregados". Esse projeto de

\footnotetext{
${ }^{18}$ A matéria de 3 de julho de 1955 dedica apenas os últimos parágrafos às discussões sobre terras em Entre Rios; a ênfase está no aumento da mortalidade infantil na Região de Guarapuava (FOLHA DO OESTE, 03/07/1955).
} 
autoria do Deputado Antonio Lustosa de Oliveira não foi aprovado na Assembleia Legislativa do Paraná, motivo pelo qual não se sabe o paradeiro dessas famílias nem se receberam as indenizações.

A partir das matérias transcritas até o referido momento, percebem-se dois movimentos que envolvem as terras de Entre Rios: um por parte do Governo do Estado com os fazendeiros que resolveram ceder suas terras em troca das terras do norte do Estado, acordo firmado por meio de contrato 1955 , mas não cumprido; outro se refere ao Governo do Estado com a Cooperativa Agrária que representa os Suábios do Danúbio. Nesse processo, o Governo entregaria as terras para os imigrantes, pelo fato de estes terem comprados as terras dos fazendeiros; e em troca os imigrantes receberiam terras no norte do Estado para negociar com terceiros. Essa ação também não foi executada, pela burocracia do governo que possivelmente não via interesse nisso. Além desses movimentos, a desapropriação das terras de Entre Rios atingiu outro grupo, os descendentes dos ex-escravos de Balbina, assunto detalhado no tópico seguinte.

\section{As terras do Paiol de Telha em En- tre Rios}

Segundo Meira (1992), com o episódio da aquisição das fazendas de Entre Rios, por volta de 40 famílias de descendentes de ex-escravos ficaram desalojadas, o que ocorreu pelo fato de inicialmente serem amparadas pelos fazendeiros que viviam neste espaço, cedendo uma porção de terra para retirar seu sustento. $\mathrm{O}$ fato de os descendentes de ex-escravos serem amparados pelos fazendeiros deve, contudo, ser questionado, uma vez que essas terras foram deixadas em testamento para os descendentes.

O texto de Adriana Cararo et al. $(2014)^{19}$ contesta essa informação

${ }^{19}$ Segundo os autores, o artigo, publicado nos Anais do VII Encontro Estadual de Estudos Territoriais e II Jornada de Pesquisadores sobre a Questão Agrária no Paraná, apresenta resultados parciais de discussão originada no curso de mestrado do Programa de Pós-Graduação em História da Universidade Estadual de Ponta Grossa (CARARO et al., 2014). e apresenta um histórico dessas terras e de seus conflitos. Em 1860, Balbina Francisca de Siqueira Cortes, que faleceu em 1868, deixou em testamento para seus onze ex-escravos a fazenda Capão Grande. Posteriormente, ocorreram disputas por parte dos familiares da proprietária, de grileiros e de colonos pela posse dessas terras, devido à imigração dos Suábios em 1951.

Outros elementos também são destacados no texto de Cararo et al. (2014), como a convivência pacífica até a expulsão dos descendentes em 1970. Contudo, o texto não deixa claro quem motivou a expulsão dessas famílias. Os anos seguintes também tiveram novos episódios: em 1981, o evento ganhou visibilidade nacional pelo fato de o Instituto de Terras e Cartografias (ITC) manifestar interesse sobre o direito dos descendentes de posse dessas terras; no ano de 1991, a Cooperativa Agrária ganhou ação de usucapião; em 1990, aconteceu a criação de uma Associação dos descendentes dos ex-escravos, quando foi criado o Assentamento Paiol de Telha, na Colônia Socorro, em Entre Rios, como forma de solucionar provisoriamente o conflito.

Em 2005, ocorreu o reconhecimento de território quilombola ${ }^{20}$ pela Fundação Palmares: "No ano de 2005, a Fundação Palmares reconheceu a comunidade composta por descendentes dos herdeiros de Balbina, como quilombo, passando esta a se denominar Comunidade Quilombola Invernada Paiol de Telhas" (CARARO et al., 2014, p. 7-8). Tal fato indica uma mudança de nomenclatura, bem como um processo, pautado pelo Decreto n. $^{\circ} 4.887$, de 20 de novembro de $2003^{21}$, de reconheci-

\footnotetext{
${ }^{20}$ Segundo Ferreira (2012), o termo quilombolas ou quilombo (Kílombò) apresenta significados com base em sua historicidade. Inicialmente, designava grupos contrários ao sistema escravista no Brasil Colônia, termo trazido do continente africano pelos povos de língua banto, sujeitos que não se subordinavam a uma escravidão imposta. O retorno a esse termo, no discurso oficial, foi utilizado na Constituição de 1988 para designa a reparão a a reparç̌a aos dasos causados pela escravidăo negra. Atualmente, esse termo tem sido utilzado para garantir um teritorio de direito dos que habitavam as terras dos quilombos, a partir da autoatribuição

${ }^{21}$ O Decreto n. ${ }^{\circ} 4.887$, de 20 de novembro de 2003, regulamenta a identificação, o reconhecimento, a delimitação, a demarcação e a titulação de terras de remanescentes de comunidades quilombolas (CARARO et al., 2014, p. 4).
} 
mento gerado pelo Instituto de Colonização e Reforma Agrária (INCRA).

Outra informação sobre o Paiol de Telha foi apresentada pela Organização Terra de Direitos ${ }^{22}$ (2014): o INCRA reconheceu o Paiol de Telha como o primeiro Território Quilombola do Paraná. Com esse reconhecimento em portaria, oficializam-se os limites do território, abrindo discussões para o decreto de declaração de interesse social da área e viabilizando uma futura desapropriação.

A mesma informação foi confirmada pelo Ministério do Desenvolvimento Agrário (MDA) (2014) em nota publicada no dia 21 de outubro de 2014. Segundo a reportagem, o Território Quilombola Invernada Paiol de Telha foi reconhecido em cerimônia no município de Reserva do Iguaçu, Paraná, iniciando-se, assim, o processo de regularização do território da comunidade. Outros dados também são apresentados nessa notícia, como o número de hectares que seria destinado a essa comunidade: 1,5 mil que beneficiarão 300 famílias de descendentes de ex-escravos.

Em 2015, a Organização Terra de Direitos apresentou novas informações sobre as terras em disputa. Em 22 de junho desse mesmo ano, a Presidente Dilma Rousseff assinou o decreto de desapropriação do território Paiol de Telha (TERRA DE DIREITOS, 22/06/2015). Em novembro de 2015, a $11^{\text {a }}$ Vara Federal de Curitiba emitiu parecer favorável ao processo, garantindo a posse definitiva de dez hectares, além de outros 168 hectares que seriam concedidos até o final daquele ano (TERRA DE DIREITOS, 18/09/2015).

A partir do que foi apresentado, percebe-se que as disputas pelas terras de Entre Rios, especialmente as que envolvem as do Paiol de Telha, ainda não foram e, talvez, nunca serão encerradas. Muitos conflitos ainda virão, envolven-

${ }^{22}$ A Organização Terra de Direitos surgiu em 2002, tendo como objetivo a promoção dos direitos humanos com ênfase em direitos econômicos, sociais, culturais e ambientais. Atua com uma equipe de assessores populares em Santarém (no Pará), em Curitiba, no interior do Paraná e em Brasília (no Distrito Federal) (TERRA DE DIREITOS, 2015). do o governo, os Suábios e os descendentes de ex-escravos.

\section{Considerações Finais}

Conforme já discutido em todo o texto, as discussões sobre as terras de Guarapuava, especialmente na localidade de Entre Rios, permanecem até os dias atuais. Tais discussões tiveram início na década de 1950 com a imigração dos Suábios do Danúbio e se desenrolam, atualmente, com as disputas pelas terras do Paiol de Telha. Nesse sentido, este texto contribuiu com o estudo da temática, ao apresentar o modo como foram motivados esses conflitos e como ocorre a desapropriação da área pelo Governo do Estado do Paraná.

A partir da análise do jornal $F o$ lha do Oeste, produzido no município de Guarapuava, perceberam-se discussões entre o Governo do Paraná, os Suábios e os fazendeiros; e, por meio das informações da Organização Terra de Direitos, verificaram-se discussões sobre o Paiol de Telha. É importante salientar, ainda, que o jornal Folha do Oeste tinha interesse no processo de desapropriação das terras de Entre Rios, pelo fato de seu fundador ter possuído terras naquela localidade. $\mathrm{O}$ político e empresário Antonio Lustosa de Oliveira também foi atingido pelo Decreto $\mathrm{n}^{\circ}$. 1.229, de 18 de maio de 1951 .

$\mathrm{Na}$ década de 1950, observaramse no referido semanário dois movimentos decorrentes do processo de desapropriação: um dos fazendeiros que aceitaram receber terras no norte do $\mathrm{Pa}$ raná em troca das suas em Entre Rios, e outro dos fazendeiros que tiveram imediatamente suas terras compradas pela Cooperativa Agrária (representante dos Suábios), motivo pelo qual o Governo do Estado deveria fornecer terras no norte para a Cooperativa. Pelas matérias do jornal, não ficou explícito se esses dois movimentos foram finalizados.

Com relação às disputas pelas terras do Paiol de Telha na mesma lo- 
calidade de Entre Rios, estas são originárias do século XIX, quando uma fazendeira deixou em testamento sua propriedade para seus ex-escravos, motivando conflito com familiares, com grileiros e com os Suábios que adquiriram essas terras. Alguns fatos significativos que marcaram esse processo são a criação do Assentamento Paiol de Telha, em 1990, e o reconhecimento pelo INCRA do Território Quilombola Paiol de Telha, em 2014. Além disso, outros episódios correlatos serão realizados nos próximos anos, como se percebe pelas informações de que o organismo governamental pretende fazer uma revisão nas terras desse Quilombo.

Em suma, este texto enfatiza que toda localidade possuiu disputas, tensões e conflitos. Na localidade de Entre Rios, isso não ocorre de forma diferente, havendo conflitos inacabados, com décadas de duração, entre proprietários e imigrantes.

\section{Referências}

1. CARARO, A. et. al. Paiol de Telhas: memória e constituição territorial "quilombola" em Guarapuava, Paraná. In: VII Seminário Estadual de Estudos Territoriais e II Jornada de Pesquisadores sobre a Questão Agrária no Paraná.2014, Ponta Grossa. Anais... Ponta Grossa: UEPG, 2014. p. 1-12. Disponível em: $<$ http://www3.uepg.br/seet/wp-content/ uploads/sites/5/2014/08/PAIOL-DE-TELHAS- MEM $\%$ C3\%93RIA-E-CONST I T U I \% C $3 \% 87 \%$ C $3 \% 83$ O T E R R I T OR I A L - \% E $2 \% 80 \%$ 9CQUILOMBOLA $\%$ E2\%80\%9D-EMGUARAPUAVA-PARAN\%C3\%811. pdf $>$. Acesso em: 28 fev. 2015.

2. COLONOS para Guarapuava. Folha do Oeste, Guarapuava, Ano III, nº. 107, 10 jun. 1951 (a).

3. COLONIA em Entre Rios. Folha do Oeste, Guarapuava, Ano III, $\mathrm{n}^{\circ} .107,10$ jun. 1951 (b).

4. DEFENDENDO os interesses de Guarapuava. Folha do Oeste, Guarapuava, Ano I da $3^{\mathrm{a}}$ fase, $\mathrm{n}^{\mathrm{o}}$. 39, 13 jun. 1954.

5. ELFES, A. Suábios no Paraná. Curitiba: [s. n.], 1971.

6. ESTA terra tem dono! Folha do Oeste, Guarapuava, Ano III, nº. 107, 10 jun. 1951 (c).

7. FERREIRA, S. R. B. Quilombolas. In: CALDART, Roseli. et. al (orgs). Dicionário da Educação do Campo. Rio de Janeiro/São Paulo: Expressão Popular, 2012.

8. GÄRTNER, M. Alguns elementos para a construção de uma História Ambiental do processo de "europeização" da paisagem do Distrito de Entre Rios, Guarapuava, Paraná. 2014. 86f. Dissertação (Mestrado em História) - Universidade Estadual do Centro-Oeste (UNICENTRO), Irati.

9. INTERESSES de Guarapuava. Fo- 
lha do Oeste, Guarapuava, Ano II da $3^{\mathrm{a}}$ fase, $n^{\circ} .58,31$ out. 1954.

10. INTERESSES de Guarapuava Volta a defendê-los, na Assembléia Legislativa, o Dep. Lustosa de Oliveira. Folha do Oeste, Guarapuava, Ano II da $3^{\mathrm{a}}$ fase, $\mathrm{n}^{\mathrm{o}} .95,7$ ago. 1955.

11. LUCA, T. R. de. História dos, nos e por meio dos periódicos. In: PINSKY, Carla Bassanezi. Fontes Históricas. São Paulo: Contexto, 2008.

12. MARIA, M. de F. A. Crônicas da alta sociedade: Discursos, representações e cotidiano nas colunas sociais do jornal Folha do Oeste (Guarapuava, PR, 1959-1964). 2011. 137 f. Dissertação (Mestrado em História) - Faculdade de Ciências e Letras, Universidade Estadual Paulista, Assis.

13. MARTINS, S. M. Pioneiros do vale de Entre Rios 1818-1951. Guarapuava: Edição do autor, 1992.

14. MINISTÉRIO DO DESENVOLVIMENTO AGRÁRIO. Governo Federal reconhece território quilombola Paiol de Telha no Paraná. 2014. Disponível em: <http://www.mda.gov.br/sitemda/ noticias/governo-federal-reconheceterrit $\% \mathrm{C} 3 \% \mathrm{~B} 3$ rio-quilombola-paiol-de-telha-no-paran\%C3\%A1 >. Acesso em: 5 mar. 2015.

15. MORTALIDADE INFANTIL no Oeste Paranaense. Folha do Oeste, Guarapuava, Ano II da $3^{\text {a }}$ fase, $n^{\circ} .90,3$ jul. 1955.

16. OLIVEIRA, C. B. de; BARBOSA, M. C. Jornais e usos do passado: a Gazeta do Povo e o passado atualizado: In: ASSOCIAÇÃO BRASILEIRA DE PESQUISADORES DE HISTÓRIA DA MIDIA. Anais. Porto Alegre: Alcar, 2011. Disponível em: $<$ http://www.ufrgs.br/alcar/encontrosnacionais-1/encontros-nacionais/8o-encontro-2011-1/artigos/nais $\% 20 \mathrm{e} \% 20$ usos $\% 20 \mathrm{do} \% 20$ passado $\% 20 \mathrm{a} \% 20 \mathrm{Ga}-$ zeta $\% 20$ do $\% 20$ Povo $\% 20 \mathrm{e} \% 20 \mathrm{o} \% 20$ passado $\% 20$ atualizado.pdf/view >.
Acesso em: 28 fev. 2015

17. RABAÇA, C. A.; BARBOSA, G. G. Dicionário essencial de comunicação. Lexikon, 2014.

18. SANTOS, R. B. Migração no Brasil. São Paulo: Scipione, 1997.

19. SANTOS, R. dos. Discursos sobre Imigração no jornal Folha do Oeste-Guarapuava, Paraná (1946-1960). 2015a. 113f. Dissertação (Mestrado em História) - Universidade Estadual do Centro-Oeste (UNICENTRO), Irati. Disponível em: < http:// www2.unicentro.br/ppgh/files/2015/07/ Disserta_o_de_Rodrigo_dos_Santos $562 \mathrm{a} 8 \mathrm{c} 0 \overline{9} 85 \overline{\mathrm{c} 01 . p d f}>$. Acesso em 23 abr. 2016.

20. Refugiados da $2^{\mathrm{a}}$ GuerraImigração para o Brasil. Leituras da História, ano VI, n. 84, p. 32-38, 2015 b.

21. SANTOS, R. dos; ALMEIDA, M. L. de; SCHÖRNER, A. 'Alienígenas do pós-guerra: percepções sobre os displaced persons entre 1945-1960'. In: V Colóquio Nacional Cultura e Poder. Anais. Campo Mourão. 2015. p. 260280. Disponível em: <http://www.fecilcam.br/culturaepoder/wp-content/ uploads/2015/09/Anais-VColoquio. pdf $>$. Acesso em: 23 dez. 2015.

22. SHEPHARD, B. A longa estrada para casa: restabelecendo o cotidiano na Europa devastada pela guerra. São Paulo: Paz e Terra, 2012.

23. SILVA, W. P. da. De Lustosa a João do Planalto: A Arte Política na Cidade de Guarapuava (1930- 1970). Guarapuava: Editora Unicentro, 2010.

24. STEIN, M. N. O oitavo dia: produção de Sentidos Identitários na Colônia Entre Rios - PR (segunda metade do século XX). Guarapuava: UNICENTRO, 2011.

25. TERRA DE DIREITOS. Incra reconhece território da comunidade quilombola Paiol de Telha, primeiro do Paraná. 2014. Disponível em: $<\mathrm{http}: / /$ terradedi- 
reitos.org.br/2014/10/20/incra-reconhece-territorio-da-comunidade-quilombola-paiol-de-telha-primeiro-do-parana/> . Acesso em: 5 mar. 2015.

26. . Quem somos. 2015. Disponível em: $<$ http://terradedireitos.org. br/quemsomos-2/>. Acesso em: 5 mar. 2015.

$27 . \quad$ Quilombolas avançam: Dilma assina decreto de desapropriação do território do Paiol de Telha. (22/06/2015) Disponível em: < http:// terradedireitos.org.br/2015/06/22/quilombolas-avancam-dilma-assina-decreto-de-desapropriacao-do-territoriodo-paiol-de-telha/>. Acesso em: 23 abr. 2016.

28. . Um passo mais rumo à vitória: Quilombola Paiol de Telha avança na retomada do seu território. (18/09/2015). Disponível em: < http:// terradedireitos.org.br/2015/09/18/um -passo-mais-rumo-a-vitoria-quilombo -paiol-de-telha-avanca-na-retomadado-seu-territorio/> Acesso em: 23 abr. 2016. 